\title{
The influence of habitual dietary intake on bone density in pre-menopausal women
}

\author{
L. Wilson, S. Lanham-New, K. Hart and L Tripkovic \\ Department of Nutrition and Metabolism, Institute of Biosciences and Medicine, Faculty of Health and Medical Sciences, \\ University of Surrey, Guildford GU2 7XH, UK
}

To date, extensive research has been conducted examining the effect that ageing and the habitual diet may have on the bone health of post-menopausal women ${ }^{(1,2)}$ however, little data is available for pre-menopausal women ${ }^{(3)}$. At present it is unclear as to whether young and middle-aged women are at a tangible risk of poor bone health and if so, what factors may be influencing this perceived risk prior to the menopause. The current study aimed to assess habitual dietary intake and volumetric bone mineral density (vBMD) in pre-menopausal women.

In total 41 healthy, pre-menopausal women of normal weight (BMI $21.5 \pm 2.2 \mathrm{~kg} / \mathrm{m}^{2}$ ), aged $34.1 \pm 10.7$ years were recruited as part of an RCT trial, with cross sectional analysis performed for this specific sub-study. The women were divided into two groups - aged 20-34 years $(n=20)$ and 35-49 years $(n=21)$. Nutrient intake was assessed with a 4-day estimated food diary and vBMD was measured via peripheral Quantitative Computed Tomography (pQCT).

For the cohort analysed as a whole ( $n$ 41), no significant correlations were found between habitual dietary intake and vBMD, nor was there a significant relationship between age and vBMD. The younger age category $\left(n 20,24.0 \pm 3.5 \mathrm{years}, \mathrm{BMI} 20.7 \pm 1.90 \mathrm{~kg} / \mathrm{m}^{2}\right) \mathrm{showed}$ few associations between diet and bone health, except for a significant positive association between Stress Strain Index (SSI) and vitamin D intake $(P<0.009)$ Fig. 1 ; this is despite relatively low mean intake values for vitamin D within the group $(2.49 \pm 2.46 \mu \mathrm{g} / \mathrm{day})$.

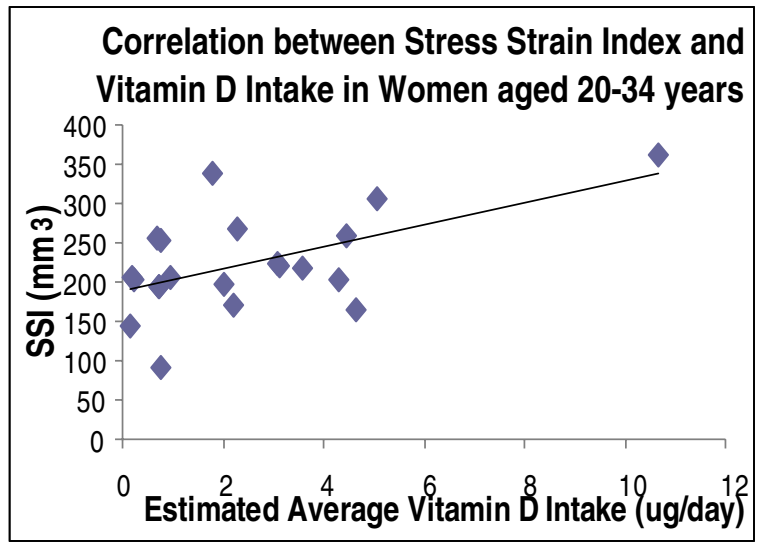

Figure 1: SSI $v s$. daily vitamin D intake $(\mu \mathrm{g} /$ day $)$

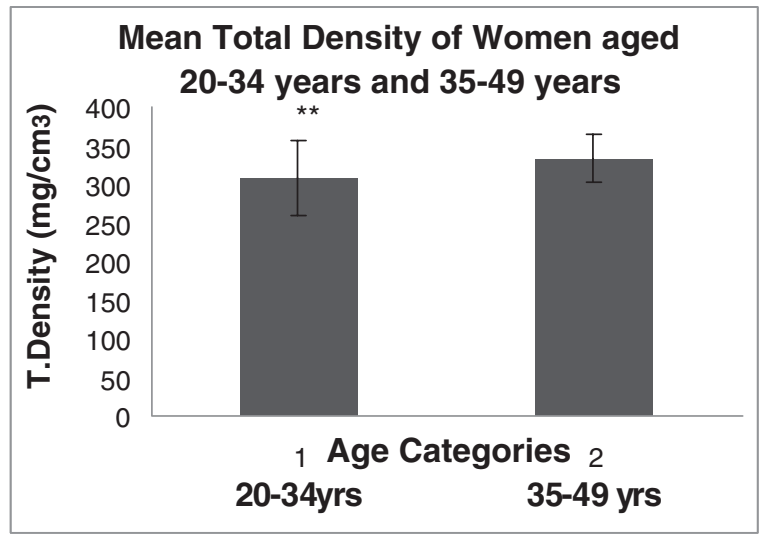

Figure 2: Comparison of mean total density between ages

The older age group $\left(43.8 \pm 4.03\right.$ yrs BMI $\left.22.3 \pm 2.24 \mathrm{~kg} / \mathrm{m}^{2}\right)$ showed a strong significant association between age and both total density $(P<0.024)$, and the T Score for total density $(P<0.023)$. Vitamin D intake was not associated with vBMD, however significant associations were found between SSI and absolute daily intakes for energy $(P<0.009)$, fat $(P<0.03)$, carbohydrate $(P<0.004)$, dietary fibre $(P<0.01)$, potassium $(P<0.009)$, calcium $(P<0.04)$ and magnesium $(P<0.02)$. When comparing between the age groups $($ Fig. 2$)$, a significant difference was found for both total density $(P<0.05)$ and the T Score for total density $(P<0.05)$.

This study demonstrates that the influences on bone health are difficult to discern when focussing solely on dietary intake, especially for the younger premenopausal women. However, the influence of dietary intake on bone density in the older premenopausal women showed some interesting associations and further research is warranted.

This work was funded by the BBSRC DRINC Programme (Grant No.BB/I006192/1). The views expressed are those of the authors alone.

1. Hardcastle AC, Aucott L, Fraser WD et al. (2011) Eur J Clin Nutr 65, 378-385.

2. Kim J, Lim SY, Kim JH (2008) Asia Pac J Clin Nutr 17, 270-275.

3. Beasley JM, Ichikawa LE, Ange BA et al. (2010) Am J Clin Nutr 91, 1311-1316. 